Journal of Architectural Research and Development

Review Article

\title{
Measures for Government Supervision Department to Strengthen Supervision on Safety Production of Construction Enterprises
}

Yan Zhao

Qingdao Chengyang Construction Engineering Service Center, Qingdao 266109, Shandong Province, China

\begin{abstract}
Safety production has always been a concern. In the field of construction, the supervision of safety production can be roughly divided into internal supervision and external supervision. External supervision is usually carried out by specific government regulatory departments. The trend of government supervision departments to strengthen the safety production management of construction enterprises is obvious, and a series of deficiencies in the supervision need to be effectively made up. In the new era, the supervision of work safety needs to be further strengthened, and the role and value of supervision need to be fully reflected. This paper will specifically analyze the current situation of the government supervision department on the safety production of construction enterprises, and put forward more effective supervision strategies.
\end{abstract}

Key word: Government sector; Construction enterprises; Safe production

Publication date: July, 2020

Publication online: 31 July, 2020

*Corresponding author: Yan Zhao, ma1392020@163. com

On the whole, the supervision level of the government on the safety production of construction enterprises has been improved to a certain extent, and before the construction, the enterprises have more and more cooperated with the supervision activities of the functional departments. However, under the influence of various factors, the supervision department has exposed some problems in the supervision of safety production of construction enterprises, which shows that there is a large space for adjustment and Optimization in the implementation of specific supervision activities. It is an indisputable fact that the regulatory authorities in some regions are unable to perform the corresponding duties well. In view of this, it is necessary and important to explore a better strategy for safety production supervision.

\section{Overview of government supervision on safety production of construction enterprises}

It is of great significance for the government regulatory departments to supervise the safety production of construction enterprises, which is also the necessary guarantee in the construction of project construction of construction enterprises ${ }^{[1]}$. The project construction process of construction enterprise itself is a dynamic process, and the construction period of large-scale project is often long. In this state, the weak safety awareness, and the lack of internal safety management in enterprises can easily lead to the occurrence of safety accidents, and the supervision conducted by the supervision department can effectively weaken the actual risk of safety accident risk. After the government regulatory departments effectively perform the corresponding regulatory functions and timely discover and investigate the relevant hidden dangers, the safety production and construction environment of construction enterprises can also be effectively optimized. For the government supervision department, it naturally needs to effectively consider the safety production supervision of construction enterprises. 


\section{The current situation of government supervision on safety production of construction enterprises}

\subsection{The frequency of supervision is obviously insufficient}

In the supervision of safety production of construction enterprises carried out by the government regulatory departments, the frequency of supervision is relatively low, and the obvious lack of supervision frequency also leads to many hidden dangers that can not be found in time, and the actual effectiveness of external supervision led by supervision departments will be weakened to varying degrees ${ }^{[2]}$. On the one hand, the regulatory resources of the government regulatory authorities are relatively limited. In unit time, when the actual number of projects under construction of construction enterprises in the region is large, it is difficult for the regulatory authorities to carry out comprehensive safety production supervision, and the supervision frequency will naturally be in a relatively low state. On the other hand, the regulatory authorities in some areas did not find their own positioning, the regulatory concept is also very old, the lack of ideological awareness leads to the mechanical characteristics of the actual supervision work is obvious. It is also because of the low actual frequency of external supervision led by regulatory authorities, it is usually difficult to improve the regulatory effect.

\subsection{Lack of focus in actual supervision}

The lack of supervision focus is also obvious in the safety production related supervision of construction enterprises conducted by government regulatory departments. Taking the safety production supervision of specific enterprises and specific projects as an example, the supervision departments need to pay attention to a variety of supervision levels in a unit time, while in a specific region, the number of enterprises and projects that the regulatory authorities need to implement synchronous supervision will also show different characteristics due to seasonal factors. Many regulatory personnel are still in accordance with the inherent thinking and mode of supervision, and some construction enterprises have accumulated sufficient "experience" to deal with the supervision of regulatory authorities. In this state, once the regulatory authorities are unable to clarify the basic focus in the actual supervision and make flexible adjustments, the supervision by the regulatory authorities is easy to become a mere formality. Over time, the effectiveness of regulation will be weakened. To rely on the development of regulatory activities to ensure the safety of construction enterprises, project construction will become more difficult. This shows that the lack of focus in the actual supervision is the specific problem in the corresponding regulatory activities.

\subsection{Decoupling of supervision and guidance}

In the safety production supervision of construction enterprises by the government supervision department, the phenomenon of decoupling between supervision and guidance is very common, which has become a specific problem in the corresponding supervision activities. In the actual supervision work, it is not difficult to find that many construction enterprises' safety awareness is very weak, not only that, it is difficult to effectively carry out safety production and construction organization. However, the effectiveness of administrative punishment is relatively low. In the actual work, even if the supervision department has carried out administrative punishment, some construction safety risks cannot be effectively solved. Government supervision has the basic power of supervision and administrative punishment, but at the same time, it should also give the corresponding enterprises necessary guidance and help in safety production and construction. Once the supervision and guidance are decoupled, the contribution of supervision to the solution of some substantive problems will be greatly reduced, and the supervision activities cannot provide sufficient support for the safety production and construction environment.

\section{Effective supervision strategy of government supervision department on safety production of construction enterprises}

\subsection{Selective increase of regulatory frequency}

The government regulatory departments should pay attention to the moderate improvement of supervision frequency in the supervision of safety production of construction enterprises, and selective improvement of supervision frequency is also an effective way to further enhance the regulatory role ${ }^{[3]}$. For example, in Northeast China, the seasonal characteristics of project construction are very obvious. Therefore, the 
government regulatory authorities should increase the corresponding supervision frequency in summer and autumn every year, and release the signal of strengthening supervision through the increase of supervision frequency as much as possible, so that the corresponding construction enterprises can have more awareness of safety production and construction. In addition, it is not difficult to find that the absence of external supervision is usually one of the causes of accidents by analyzing the causes of safety accidents in some construction enterprises. Therefore, it is very important to selectively enhance the supervision frequency of safety production, so as to strengthen the supervision. In this case, the supervision department can find the corresponding problems more timely, and various problems existing in the safety production and construction of construction enterprises can be more effectively solved.

\subsection{With the help of the innovation of supervision form, the key points of supervision are highlighted}

There are many factors that can have an impact on the regulatory functions of government regulatory departments and the effectiveness of regulatory activities. Among them, the selection of regulatory means and the clarity of regulatory focus are more direct factors. From the perspective of improving the actual effectiveness of regulatory activities, it is very important to highlight the regulatory focus with the help of innovation and diversification of regulatory forms. For example, the regulatory authorities can effectively link active supervision with passive supervision, and receive the information from the public for targeted supervision by unblocking the corresponding online reporting platform. This practice can usually help the regulatory authorities to clarify the direction and focus of supervision in a timely manner. In addition, the government regulatory departments can also analyze the types and causes of common construction safety problems in the region under the big data thinking, so as to clarify the supervision focus, and carry out specific innovation in the selection of supervision means in combination with the actual needs of corresponding regulatory activities.

\subsection{Targeted guidance combined with regulatory issues}

Combined with the performance of a series of regulatory issues, it is equally important to provide targeted guidance, which is also a practical problem that government regulatory departments can not ignore when performing the corresponding regulatory functions. For example, some enterprises can not effectively solve the problems in production safety and construction in a short period of time. In this case, the government regulatory authorities should not only impose corresponding penalties, but also help the corresponding enterprise entities to clarify the solutions of safety production and construction problems by issuing rectification proposals, so as to solve the corresponding problems and restore the normal production and construction order For effective help. Government supervision departments can also provide necessary help and support for construction enterprises to carry out project construction safely by issuing corresponding safety production and construction manual, publishing supervision standards on the network, and strengthening the publicity of safety production and construction supervision knowledge. After the strict supervision and effective guidance are fully linked together, the regulatory and service attributes of government regulatory departments can be effectively highlighted, and the role of regulatory activities can be further improved.

\section{Conclusion}

The government supervision departments related to the safety production supervision of construction enterprises need to pay more attention to their own supervision functions in the new period, and strengthen the supervision of the corresponding construction activities of relevant enterprises in the region. For the deficiencies and problems existing in the supervision, the corresponding departments should make up for and solve them based on systematic examination and analysis. In addition, the regulatory authorities need to constantly summarize the experience of safety production supervision of construction enterprises, and carry out more systematic adjustment and Optimization in the supervision based on the actual supervision experience, which is also an effective way to continuously improve the supervision level and better play the regulatory effectiveness.

\section{Reference:}

[1] Yi HM. On how the government regulatory departments strengthen the supervision of safety production of construction enterprises[J]. Building materials and decoration, 2019(23): 
44-45.

[2] Gu CL. How government departments effectively strengthen the supervision of enterprise safety production[J]. Modern enterprise culture, 2019(35): 145-146.
[3] Yang YF. The problems and Countermeasures of the government in the safety production supervision of clothing enterprises[J]. Enterprise reform and management, 2018(4): 67-68. 